\title{
EMOTIONAL WELLNESS AND MANAGEMENT EFFECTIVENESS WITHIN THE PUBLIC HEALTHCARE SECTOR
}

\author{
GERRIT STIMIE \\ Department of Human Resource Management \\ Rand Afrikaans University \\ CHRISTA FOUCHÉ \\ School of Social and Cultural Studies \\ Massey University, Auckland
}

\begin{abstract}
This article reports on a study undertaken to assess the state of emotional wellness of employees as well as management effectiveness within the public healthcare sector. For this purpose a Johannesburg public hospital was used as a case study. A qualitative approach was utilized, but it was decided to include triangulation of methodology to increase the reliability of the data. Both a self-administered questionnaire and focus group interviews were used as data gathering instruments. Forty-six focus group interviews were conducted and a total of 850 employees participated in these interviews. A total of 388 employees returned their questionnaires (response rate $=32 \%$ ). A number of key issues relating to management effectiveness and employee wellness were identified. The findings and their implications will be explored further.
\end{abstract}

\section{OPSOMMING}

Hierdie artikel rapporteer 'n studie wat onderneem is om werknemers se stand van emosionele welsyn sowel as bestuursdoeltreffendheid binne die openbare gesondheidsdienssektor te ondersoek. Vir hierdie doel is 'n Johannesburgse openbare hospitaal as 'n gevalstudie gebruik. 'n Kwalitatiewe benadering is gebruik, maar daar is besluit om van intermetodiese kruisvalidasie gebruik te maak, sodat die betroubaarheid van die data verhoog kan word. Beide 'n self-voltooiingsvraelys en fokusgroeponderhoude is gebruik as data-insamelingsinstrumente. Ses-enveertig fokusgroeponderhoude is gevoer wat 'n totale groep van 850 werknemers betrek het. 'n Totaal van 388 werknemers het die vraelyste voltooi (responskoers $=32 \%$ ). 'n Aantal kernvraagstukke wat met bestuursdoeltreffenheid en werknemerwelstand verband hou, is geïdentifiseer. Die bevindinge en hul implikasies sal verder ontgin word.

\section{BACKGROUND}

A study was conducted in order to understand the full impact of the current lack of emotional wellness and poor management efficiency within Public Hospitals. Because of the enormity of the health system, it was decided to conduct this within the parameters of only one Public Hospital. For this purpose a Johannesburg public hospital was chosen. The implementation of this project as well as the results thereof will be addressed in this article.

The Department of Health in South Africa

In 1999 the National Department of Health published the "Health sector strategic framework 1999-2004" document (HSSF, 2000). According to this document up to 40 per cent of all South Africans live in poverty and 75 per cent of these live in rural areas where they are deprived of access to health services. The aim of the Department of Health in South Africa is therefore to promote healthcare that is affordable and accessible to all South Africans through a caring and effective national health system based on the primary health-care approach (Health Sector Strategic framework, 2000).

State and privately subsidised permanent and mobile clinics form the backbone of primary and preventative health care in South Africa. In addition to clinics, provincial hospitals play a vital role in providing secondary and tertiary care as well as the training of physicians, nurses and supplementary health personnel. The Health Sector Strategic Framework 2000 (HSSF, 2000) document claims that the public health sector is responsible for treating almost $80 \%$ of all South African citizens. State hospitals are often handicapped by money, equipment and personnel shortages, which again have a direct impact on the level of service to patients as well as to the academic support for the practice of medicine.

The Health Sector Strategic Framework (HSSF, 2000) document further includes a ten-point plan to accelerate quality health

Requests for copies should be addressed to: G Stimie, Department of Human Resource Management, RAU University, PO Box 524, Auckland Park, 2006 service delivery. According to this document the key message that constitutes the essence of what needs to be done in the following years is:

- The consolidation of achievements in improving access to care and advancing equity;

- To deal decisively with the HIV/AIDS epidemic and its ramifications which threatens to undo our developmental gains; and

- To stabilise the hospital sector, including the need to promote greater efficiency and consider additional sources of funding for this sector; and adopt a multidimensional approach to ensure steady improvement in quality of care.

Sections 3.5 of the strategic plan deals specifically with the "Revitalisation of public hospitals". In section 3.5.3 specific reference is made to: "Decentralising hospital management for improved efficiency and quality of care": The following is a direct quote from this document:

"Numerous investigations of our hospital sector reveal significant levels of inefficiencies. A fundamental contributor to this is the archaic management structures, systems and culture. This often causes management paralysis. A compounding, related, element is the pervasive lack of appropriate management competencies and capacity among our management teams. We need to accelerate the implementation of our decision to decentralise management authority, which should be completed during this 5-year term."

From the above it is clear that the department of health places huge emphasis on management effectiveness and competencies and they realise the need for dynamic management structures, systems and cultures. In an attempt to even further enhance employee's competencies, the department of Health wants to implement an Employee Assistance Programme (EAP) in order to help employees deal with the emotional trauma that is experienced on a daily basis. Management effectiveness and employee wellness is thus embedded in the Department of Health's transformation plans. 
Brief overview of the recent history of a Johannesburg public hospital

In an interview with the current $\mathrm{CEO}$ of a Johannesburg public hospital, it was stated that during the apartheid era, the this hospital used to be a white academic hospital where predominantly white managers and staff members were responsible for white patients. Apart from the fact that the hospital's name was changed to a Johannesburg public hospital, he also stated a number of other occurrences in this time of transition at the hospital after 1994.

- The racial composition of patients, staff members and management changed.

- No concerted effort was made to create a new value system or ethos within the hospital.

- In 1999 a new top management team were appointed. The "us and them" culture was very well entrenched at that stage and relationships between members of staff in general were not very healthy.

- A particularly poor relationship between management and the labour union NEHAWU existed.

- Strict budget control in Government hospitals was enforced and no overspending was allowed.

- Hospital management had no authority to discipline any staff members.

- The bed occupancy rate in the hospital increased dramatically as a result of the fact that more and more people were infected with HIV/AIDS.

- Many well skilled staff members took severance packages or resigned to join private hospitals. This, and the fact that most positions were frozen, meant that these staff members could not be replaced, and a huge middle management void was thus created.

This article is presented against the above background of a Johannesburg public hospital and with a full understanding of the challenges faced by the Department of Health.

\section{Definition of the problem}

Organisations everywhere are undergoing rapid and significant changes, driven by external as well as internal factors such as: higher customer expectations, new technologies, increased marketing dynamics, rapidly growing competition at the international level, strategic changes and new legislation (Laudon and Laudon, 1998).

The worldwide healthcare industry is also in a process of rapid transformation and the public healthcare sector in South Africa has not escaped the demands of a global economy that is forever asking more for less (Pricewaterhousecoopers, 1999). These changes have ultimately impacted on the characteristics associated with organisational effectiveness. However, despite more and more innovative solutions for Business Processes Reengineering (BPR) and Total Quality Management (TQM), the human resistance to change continues to be one of the biggest obstacles in any transformation (Bashein, 1994).

The authors of this article believe that management efficiency or the lack thereof, and emotional wellness or disease amongst employees are closely related and largely influence one another. Any change in the status of either will therefore have a direct positive or negative impact on the other. Given this to be the case the medical slogan of " $A$ doctor prescribing without diagnosing is guilty of malpractice" was used as point of departure. It was thus the aim of this study to firstly determine the general state of emotional wellness (human factor) and management efficiency (organisational performance) within the public health sector before making any change recommendations.

\section{Emotional wellness}

Historically, emotion has been a difficult topic for researchers. In the 1960s the cognitive era emerged and the human being was under the siege of very rational and logical decision-making, where emotion could only be some kind of imperfection in this well-rounded mechanism. Since the 1980s, emotion has gained some popularity again and today most will agree that the knowledge and emotions of employees are two of the most important assets for organisations to posses if they want to maintain a competitive advantage (Thomson, 1998).

However, one of the major obstacles to progress in this area has been the problem of arriving at a definition and a concept of emotion acceptable to most. Thomson (1998) refers to the hidden resources of feelings, beliefs, perceptions and values that make up an organisation's "emotional capital" and sums it up as "the hearts of the people in the business". Rumford (1996) states that when change occurs or trauma is experienced that is too sudden or too overwhelming, the emotional disease can become a deadly carcinogen, killing not only the individual but also the organisation.

It becomes increasingly obvious that an emotional climate pervades every level of human interaction inside any organisation. Steward (2000) states that we can think of emotion as a covert resource, like money, or knowledge, or physical labour, where companies need to get the job done. Real-time emotions are a large part of what managers manage and emotional labour is no small part of what trainers train and supervisors supervise. It is a big part of white-collar "work". This is true for manufacturing firms, but even more so in the rapidly expanding service sector - in department stores, airports, hotels, leisure worlds, hospitals, welfare offices and schools.

For our definition, emotional wellness would refer to the perceived, real or imagined ability to change, handle or better your circumstances (Thomson, 1998). Emotional disease as counterpart, would refer to the human emotion of being overwhelmed by a new culture, position or situation.

\section{Management effectiveness}

Generically, organisational or management effectiveness is not a term readily agreed upon and a quick scan of the literature by Miles (1980) shows a variety of definitions ranging from the acquisition of goals, to the attainment of highly efficient processes. Furthermore, assessing management effectiveness is a complex endeavour given the multiplicity and diversity of criteria, which have been, and need to be, examined. These criteria would include for example, scientific management, human relations theory, systems and contingency theory, the excellence/culture movement, and organisational learning/the learning organisation, to name the more well- known approaches (Robbins, 1987). It has been said, "effectiveness remains an enduring concern for both academics and managers and lies at the heart of all organisational theories" (Laudon \& Laudon, 1998). However, it has often been an implicit assumption in different management approaches.

A relevant concept is one developed by McKinsey and Company (Peters \& Waterman, 1982) who in 1997 revisited previous work on organisational effectiveness. More specifically, they examined the relationship between strategy, structure, and management effectiveness and found that management excellence is associated with: keeping things simple in a complex world; paying attention to the informal mechanisms within the organisation; and ascribing to the concept of innovation.

Ulrich (1999) refers to management efficiency as the structured process of planning, organising, leading and controlling a system in such a manner that the required results can be achieved and states that effectiveness is all about achieving some purpose, result, or set of goals deemed to be necessary in an organisation.

However, in the public sector this may be problematic, it has been noted, "the essential problem may be obtaining agreement about the primary purpose, intention or function of the organisation and its key objectives" (Miles, 1980). While the concept of 
effectiveness is highly complex, there has been a tendency to view it in simplistic terms, and to disregard the cultural differences within, and between, organisations (Steward, 1996). This study suggests that the meaning of management effectiveness is best understood as a subjective, socially constructed concept rather than an objective or rational fact.

\section{Project goals}

This study had the following goals:

- To determine the general state of emotional wellness and management efficiency within the Public Healthcare Sector by means of a case study whereby the results of a selfadministered questionnaire and focus group interviews, were analysed.

- To identify the most critical problem areas and possible causes within this context.

- To make specific recommendations on addressing these issues

\section{RESEARCH METHODOLOGY}

With a mandate to analyse the emotional wellness and management efficiency within hospital, it was decided to use a qualitative approach, but to include triangulation of methodology to increase the reliability of the data.

The decision to use a predominantly qualitative research approach was based on the very nature of qualitative research, best described in terms of its antipositivistic, interpretive and holistic approach. The main aim of qualitative research is to understand the social reality of the respondents and the meaning that people attach to it (Babbie, 1992). The following features of qualitative research were noted:

- Qualitative researchers discard the notion of an external, objective reality. They aim to understand reality by discovering the meanings that people in a specific setting attach to it. To them behaviour is intentional and creative, and it can be explained but not predicted.

- The qualitative researcher is subjective, interacts with the subject and accepts that $\mathrm{s} / \mathrm{he}$ cannot be detached and valuefree.

- Qualitative methodology is dialectical and interpretive. During the process of interaction between the researcher and the subject, the subject's world is discovered and interpreted by means of qualitative methods.

The interpretive paradigm was selected as the dominant theoretical framework for this study. This framework was seen as most suitable for the purpose of the study, as the interpretive social researcher examines meanings that have been socially constructed. The interpretive approach recognises that meaning emerges through interaction and is not standardised from place to place and person-to-person. The interpretive approach emphasises the importance of understanding the overall text of a conversation and, more broadly, the importance of seeing meaning in context (Rubin \& Rubin, 1995).

The researcher consequently accepts that values and views differ from place to place and group to group. This framework postulates that there is not one reality out there to be measured; objects and events are understood by different people differently, and those perceptions are the reality - or realities - that the researcher focuses on: "Interpretive researchers try to elicit interviewees' views of their worlds, their work, and the events they have experienced or observed. To reconstruct and understand the interviewees' experiences and interpretations, interpretive researchers seek thick and rich descriptions of the cultural and topical arenas they are studying and try to develop an empathetic understanding of the world of others" (Rubin \& Rubin, 1995 p. 35).

In summary, according to the interpretative paradigm:
- reality can be understood and interpreted but not predicted and controlled;

- knowledge arises from observation and interpretation; and

- data is collected and analysed through observation and interviewing.

\section{Parameters of the research}

As the researcher gained more insight, the data sources were redefined on an ongoing basis. The process of referral was systematically repeated until all focus group interviews were conducted. The following generic themes were addressed during all the interviews:

- Strategy of the hospital and respondents understanding thereof;

- The availability of materials and equipment;

- The functioning of teams;

- Communication;

- Workload

- The role of Unions in the hospital;

- The general culture or ethos within the hospital;

- The relationship between different departments in the hospital;

- Staff shortage and rotation;

- Patient profiles;

- Training and development of staff;

- Performance management; and

- Burnout and emotional wellness of employees;

As the research proceeded, the questions asked by the researchers were adapted because of the inductive model of thinking used in the study.

\section{Methods of data collection}

Focus Group Interviews

Forty-six focus group interviews were conducted. A total of 850 employees participated in these interviews. The following criteria were considered during the formation of the focus groups:

- Professional responsibility

- Organisational level

- Based on these criteria the following categories were formed:

- Top Management

- Consultants

- Doctors and Interns

- Area Managers

- Nursing

- Allied workers

- Administration and clerical workers

A number of themes relating to management effectiveness, emotional wellness of staff members, the organisational environment and general culture within a Johannesburg public hospital emerged during the focus group interviews. Some of these themes were generic while other themes were specific and only identified by participants in some of the above-mentioned categories.

\section{Self Administered Questionnaire}

Although the research design in this study was predominantly qualitative in nature, it was decided to also use a selfadministered questionnaire. The questions in Section one of the questionnaire was of a demographic nature. The questions in Section two were related to everyday work experiences. The Gallup Workplace Audit (GWA) instrument that was used has evolved over 25 years of research by Buckingham and Coffman (1999) in various studies regarding organisational and management effectiveness. It consists of an overall organisational satisfaction item and 12 items that measure the respondent's perception of his/ her work characteristics. As a composite measure the GWA has high convergent validities with overall job satisfaction measures and relates well to the business outcomes of profitability, productivity, employee wellness and customer satisfaction (Buckingham \& Coffman, 1999). 
Responses to each statement were made on a five point scale ranging from $1=$ strongly disagree to $5=$ strongly agree.

Data gathered by the focus group interviews and the distribution of the questionnaires must be seen as a simultaneous process. The one process was not leading nor flowing from the other. As the research was predominantly qualitative in nature, the questionnaires were included only to cross verify the results obtained from the facilitated interviews and the data were only analysed after completion of all interviews.

\section{Data Analysis}

Inductive reasoning was followed in the analysis of the collected qualitative data. The researcher attempted to discover key issues, recurrent issues, patterns and relationships through close scrutiny of the data. The data was analysed and interpreted by means of inductive abstraction and generalisation. The constant comparative method of Lincoln and Guba (1985) was used. In this regard the information from the questionnaires and the information gathered during the focus group interviews were constantly tested against one another to see if the same recurring themes emerged. Frequency distributions were used in the analysis of the questionnaires.

\section{RESULTS OF THE QUALITATIVE STUDY}

As indicated in the introduction to this article, the healthcare industry in South Africa is in a process of transformation, much of which is a reflection of the changing South African environment. The hospital is of no exception and it is essential to keep the recent hospital history in mind in order to put the qualitative findings in perspective. During numerous interviews with executive management it became clear that the hospital is faced by a number of transformation challenges. Some of these surfaced as generic themes, while other themes were specific and only identified by participants in some of the above-mentioned categories. These challenges include amongst other things very strict budget control, inexperienced and incompetent middle management, unhealthy management/union relationships, an ill-defined hospital culture, and general staff shortages. These and other issues will now be discussed in more detail.

\section{Themes relating to emotional wellness of employees and management effectiveness \\ An ill-defined hospital mission, vision and culture}

Talwar (1993) states that the success or failure of any institution ultimately relies on its strategies - how appropriate they are given internal and external forces, and how they are implemented. The intended strategy is however affected by the behaviours of people who are expected to carry them out. Organisational culture or ethos serves as a rudder to keep the institution's strategy on course.

Although the executive management at the hospital seems to have a relatively clearly defined strategy, the author came to the conclusion after discussion with executive management as well as members of staff that a new inclusive and representative value system and culture still need to be defined within hospital. The absence of a clearly defined value system thus complicates the implementation of the overall strategy significantly.

\section{Management's perception of the Gauteng Health Department (GHD)}

The executive management were of the opinion that that the Gauteng Health Department does not understand the harsh reality of the conditions within Public Hospitals or that the Government is not prepared to listen to their concerns and recommendations. Management was also frustrated by the small, and in their opinion, inadequate budgets as well as the fact that many positions were frozen. New staff members are inexperienced and because of the middle management void that was created since 1999 no proper mentorship system is currently in place in the hospital.

Management secondly indicated that they are frustrated by the fact that they cannot effectively discipline staff or recommend staff dismissal. In this regard management had the perception that GHD officials were always available to talk to members of NEHAWU, but this was not the case when management tried to make appointments.

\section{Management's relationship with the Unions}

Management's relationship with HOSPERSA seems to be generally healthy and will not be discussed in detail. In the light of the above mentioned reference to the June 2000 strike it should be clear that management's relationship with NEHAWU is however not particularly healthy. Management perceives NEHAWU members to be extremely aggressive and rude during management/union interaction. Management also referred to instances were union representatives harassed supervisors who attempt to discipline subordinates. Supervisors in the hospital have thus become reluctant to take any disciplinary action against union members.

\section{Staff Shortages}

The overall opinion of the participants was that the general shortage of staff has a detrimental effect on the levels of service delivery within the hospital. The management team indicated that the following factors, (in addition to the fact that all vacant positions were frozen after 1999), contributed to the severe staff shortage experienced in the hospital:

Absenteeism: Staff absenteeism seems to be an ever-growing problem. The high levels of absenteeism are related to the following:

- Student and recently qualified nurses do not get the opportunity to work in optimal conditions and to apply their theoretical knowledge, thus leaving them in a state of disillusionment;

- Nursing staff experience trauma on a day to day basis and no or very little support systems are in place to help them deal with this trauma; and

- Junior staff members are often exposed to verbal abuse by more senior staff members, doctors and service staff;

The rotation system: Because of the already existing staff shortage, nursing staff often has to be moved around in order to be available in those wards where they are most needed. Nurses are frustrated by the fact that they can't focus on a specific discipline, and either do not come to work or resign.

The consultants and doctors indicated that staff shortages contributed to the fact that doctors often have to work for up to 80 hours per week although they were only employed to work for 40 hours. They were of the opinion that these working hours did not only have a negative impact on the wellness of doctors but that it also had a very negative impact on the quality of patient care. Doctors were furthermore frustrated by the fact that they were unable to attend training courses, as they could not get time off work and of apparent financial and budgetary constraints.

\section{Non-established lines of authority}

A number of factors contribute to the fact that no clear lines of authority seem to be established within the hospital. The first of these is the fact that vacant positions were frozen after 1999 Middle management is not equipped to deal with the issues on their tables. Executive management indicated that upward delegation takes place and top management often has to deal with lower level managerial issues.

\section{Patient administration system}

Management indicated that they are extremely frustrated by the fact that no computerised patient administration system is in place. According to management, pilot studies are currently being done at other Government Hospitals and that it would be 
impossible for them to buy any system at this stage. Numerous other participants also highlighted the absence of a computerised system as a huge source of frustration.

\section{Expectations and job descriptions}

Area managers indicated that they are often uncertain what management expects from them. They largely contribute this to the lack of formal job descriptions for area managers, no orientation prior to starting their duties and little or no training afterwards. They are furthermore of the opinion that there is very little role clarification within the hospital. The perception is that they are held accountable for results without having any formal authority and without receiving all the relevant communication and information necessary to make decisions.

\section{Changing nature of the patient profile}

Employees indicated that the huge inflow of patients after political changes in 1994 without corresponding investment in material and equipment complicated their work tremendously. Another major concern was the impact that, amongst other health conditions, HIV/AIDS had on the emotional well-being of medical staff members. Senior staff members do not have time to help interns and junior doctors to cope with their working realities. It was suggested that the effect HIV/AIDS has on medical staff members should be evaluated in more detail in order to develop appropriate action plans to equip staff members to deal with this issue. This is but one health condition to be explored as a separate issue outside the scope of this study.

\section{Materials and equipment}

The participants indicated that the shortage or lack of equipment and material is especially critical. According to the nursing staff, the shortage of these and other vital equipment have a very negative impact on their ability to care for patients. Patient conditions are often aggravated by this state of affairs and claims have been made that the insufficient supply of critical material have led to the death of patients whose lives could have been saved if the necessary equipment was available.

Nursing staff were also very sceptical about the quality of equipment. The nurses indicated that they have to wait for months before broken equipment is repaired. During the waiting period nursing staff have to borrow equipment from other wards. Unit managers with equipment in working condition are however reluctant to borrow equipment for fear that they might need the equipment or that the equipment will not be returned in working condition. This often leads to arguments between wards.

\section{Disillusionment, burnout and staff counselling}

The above-mentioned structural issues have a direct impact on the emotional wellness of employees. Apart from the normal trauma experienced by all medical personnel, the growing number of HIV/AIDS patients and HIV/AIDS related deaths seem to contribute to this sense of disillusionment. Participants indicated that they often feel very stressed and in many instances feel completely burnt out. It is in this regard disturbing to note that 54 percent of participants were younger than 35. Management however confessed that more should presumably be done to help staff members deal with everyday trauma.

\section{Performance management, recognition and feedback}

No evidence of an effective performance management and feedback system could be found. Employees were of the opinion that they received very little recognition for work done, and that management often took their efforts for granted. Related to this is the issue of unclear and often nonexistent job descriptions. Administrative staff in general were of the opinion that their direct managers lack adequate management skills. Amongst other things they referred to the unsatisfactory way in which managers communicate with them, handle conflict and not really being open to listen to any of their suggestions.

\section{Lack of teamwork and group cohesion}

Little or no teamwork is currently possible within the hospital since there seems to a lack of work ethic and group cohesion. Although the relationship between members of the nursing staff seems to be generally healthy, general assistants, cleaners and porters apparently do not see themselves as part of ward teams. Area managers are of the opinion that these workers very seldom adhere to the rules of the hospital or nursing staff. They were also very frustrated by the role of NEHAWU in this regard. Area managers were of the opinion that management has lost control and that they are scared to take strong action against the union.

\section{Customer satisfaction}

The nurses were of the opinion that all the above issues have a very negative impact on customer satisfaction and on the general perception that the community have of the hospital. As they are hardly able to care for patients, they have little motivation to deal with potential patients and/or families of patients.

\section{Bureaucratic policies and procedures}

Nursing staff indicated that they are often frustrated by the (to them) unnecessary policies and procedures they have to adhere to for doing almost everything that they have to do. It is clear that policies and procedures are either not aligned with reality or not adequately communicated to people responsible for implementation.

\section{The "us and them" culture}

Although evidence of a strong 'us and them' culture with very distinct racial and cultural undertones was found within the ranks of non-medical staff members, racial tension is less evident within the ranks of nursing staff members. This culture also manifest on various levels within the ranks of clerical and administrative staff. Black participants were of the opinion that appointments and more specifically supervisory appointments are still made along racial lines, with whites being favoured.

There is also very noticeable tension between members of the two unions in the Hospital. This tension is also characterised by racial undertones where NEHAWU represent predominantly black workers and HOSPERSA represents predominantly white workers.

\section{Safety and working conditions}

Participants were concerned about their physical safety within the work environment and indicated that they are often sexually harassed by doctors, porters, patients and ambulance men and that no effective procedures are in place to protect them against this. Participants referred to instances where they were 'on call' and had to come to the hospital late at night. They indicated that they often have to work alone in a ward at night while the external doors are not closed. In addition to this nursing staff members are expected to carry drugs from the pharmacy to the wards and are afraid of being mugged on the way. Participants indicated that they are also afraid of aggressive community members who threaten to 'get them outside'.

The dirty wards and consulting rooms they had to work in also created unease. Allied workers were of the opinion that cleaning staff members were specifically to blame for this state of affairs. Participants indicated that the majority of cleaners were members of NEHAWU and that management has lost control over union members. This state of affairs had a very negative effect on patient hygiene and employees indicated 
that it was particularly unpleasant to give therapy to patients in these conditions.

\section{Training and Development}

The nurses were of the opinion that the criteria used to select nurses for further training and development was not very clear. They were also critical about the long procedure that had to be followed even if they were prepared to pay for their own studies. Supervisors are apparently not very supportive in this regard and nursing staff struggle to get study leave

\section{Communication}

Communication seems to be a major problem with various dimensions. In the first instance the medium of communication seems to be problematic. Participants indicated that feedback is often given in Afrikaans. NonAfrikaans speaking workers then often loose out on the full meaning of the message.

Secondly the vertical as well as horizontal communication channels seem to be ineffective. In this regard allied workers indicated that they are not informed about changes in hospital policies and procedures that directly affect them. Regarding horizontal communication allied workers indicated that their patients are often discharged without them being notified. Participants were also of the opinion that modern communication media such as e-mail and the Intranet is largely under utilised as a result of the poor computer infrastructure in the hospital.

\section{QUANTITATIVE RESULTS}

As indicated earlier in the article, the research design was predominantly qualitative in nature, but it was decided to also use a self-administered questionnaire. Section one of this questionnaire explored the demographic nature of the sample and will be reported on in the next discussion. The questions in Section two related to everyday work experiences and will be reported on by item. Frequency distributions were used in the analysis of these items, and the average score for all the respondents will be reported and discussed.

\section{Section 1: Demographic information}

A total of 388 employees returned their questionnaires and this equates to a response rate of 32 percent. The relatively low response rate can in itself be a reflection of management effectiveness as well as the general state of emotional well-being of employees. This notion was confirmed with the results of the focus group interviews.

The majority of employees that returned the questionnaires are between the ages of 26 and 40 . A total of 52 percent of the respondents fall within this age group. As was expected, the majority (68\%) of participants were female. The completion of the "race" question was optional and no specific conclusions can therefore be drawn from this. The returned questionnaires adequately represent all the different hospital departments and organisational levels.

Section 2: Organisational and management effectiveness Table 1 describes the twelve items of the Gallup Workplace Audit (GWA). Each item was rated on a five point scale where $1=$ strongly disagree and $5=$ strongly agree. In the following discussion, in each case the average hospital score of all the respondents are stated. The last column indicates the specific relation of the item to one of four critical management outcomes to be achieved (Buckingham \& Coffman 1999)
AVERAge hospital SCORE ON ITEMS OF THE 'Gallup Workplace Audit'

\begin{tabular}{|c|c|c|c|}
\hline \multirow{2}{*}{\multicolumn{2}{|c|}{ No Core Item }} & \multirow{2}{*}{$\begin{array}{l}\text { Average } \\
\text { Hospital Score }\end{array}$} & \multirow{3}{*}{$\begin{array}{l}\text { Relation to specific } \\
\text { business outcome } \\
\text { Emplovee Turnover }\end{array}$} \\
\hline & & & \\
\hline 1 & I know what is expected of me & 4.3 & \\
\hline & at work & & Customer satisfaction \\
\hline 2 & $\begin{array}{l}\text { I have the right materials and } \\
\text { equipment to do my work }\end{array}$ & 3.07 & $\begin{array}{l}\text { Employee Turnover } \\
\text { Customer satisfaction }\end{array}$ \\
\hline 3 & $\begin{array}{l}\text { I have the opportunity to do } \\
\text { what I do best everyday }\end{array}$ & 3.27 & $\begin{array}{l}\text { Profitability/Cost } \\
\text { Effectiveness }\end{array}$ \\
\hline 4 & $\begin{array}{l}\text { I have received recognition and } \\
\text { praise in the last seven days }\end{array}$ & 2.23 & $\begin{array}{l}\text { Profitability/Cost } \\
\text { Effectiveness }\end{array}$ \\
\hline 5 & Someone cares about me & 3.14 & $\begin{array}{l}\text { Profitability/Cost } \\
\text { Effectiveness }\end{array}$ \\
\hline 6 & $\begin{array}{l}\text { Someone encourages my } \\
\text { development }\end{array}$ & 2.89 & $\begin{array}{l}\text { Profitability/Cost } \\
\text { Effectiveness }\end{array}$ \\
\hline 7 & My opinion seems to count & 2.87 & Customer satisfaction \\
\hline 8 & $\begin{array}{l}\text { The mission of the Hospital } \\
\text { makes me feel important }\end{array}$ & 3.07 & Customer satisfaction \\
\hline 9 & $\begin{array}{l}\text { My fellow workers are } \\
\text { committed to quality work }\end{array}$ & 3.44 & $\begin{array}{l}\text { Customer satisfaction } \\
\text { Productivity }\end{array}$ \\
\hline 10 & I have a best friend at work & 2.94 & Customer satisfaction \\
\hline 11 & $\begin{array}{l}\text { In the last six months someone } \\
\text { has talked to me about my progress }\end{array}$ & 3.02 & $\begin{array}{l}\text { Customer satisfaction } \\
\text { Profitability } \\
\text { Productivity }\end{array}$ \\
\hline 12 & $\begin{array}{l}\text { I have the opportunity to learn } \\
\text { and grow }\end{array}$ & 3.02 & $\begin{array}{l}\text { Customer satisfaction } \\
\text { Productivity }\end{array}$ \\
\hline
\end{tabular}

From the information in table 1 it can be deduced that employees are generally aware of what is expected of them at work (item 1). This finding also correlates with findings made during the focus group interviews and findings made in other studies within the hospital industry (Petros 2001). Responses to Item 2 seem to be generally neutral, but it became evident during focus group interviews that employees are not very satisfied with the materials and equipment they have available to do their job everyday. This state of affair indeed does have a negative effect on staff morale and ultimately employee turnover as well as customer satisfaction. During the interviews, employees indicated that although they do their level best to make patients as comfortable as possible they are often handicapped by the lack of material and equipment.

It is disturbing to note that questions related to the focus area "What to I give?" (item 3) and ultimately to the overall profitability (or cost effectiveness in the case of a governmentsubsidised hospital) had a very low score. Within the Hospital industry it was found that Item 3 could be related to the rotation system. The relative positive response to Item 3 however does not correlate fully with the general unhappiness that was expressed during focus group interviews on the issue of rotation.

The issue of staff recognition and employee development (item 4 ) is particularly problematic (with an average score of 2.23) and can be the result of management inexperience and incompetence as well as the absence of a proper Performance Management system. A general comment during basically all focus group interviews were that staff members do not feel valued.

Although responses to Item 5 (Some cares about me) were slightly more positive, responses to Item 6 (encourages my development) were again very negative. Responses to Item 7 are related to management accessibility as well as the fact that employees are of the opinion that they make a valuable contribution and that they are trusted. The low score (2.87 on average) of this item is thus a reflection of the fact that management is not perceived to be very accessible. This draws a parallel with the general perception that employees do not feel 
valued and confirms the findings of the focus group interviews.

Participants were generally neutral about the mission and purpose of the hospital (Item 8) and there was a relatively positive response to Item 9 (My co-workers are committed to quality work), despite the fact that participants from medical disciplines indicated very strongly during focus group interviews that they were not satisfied by the service of support staff and cleaning personal in particular.

Item 10 can be related to teamwork and the fact that the support system within the hospital is seemingly inadequate. This very low score (2.94 on average) to this item can be influenced by among other things the rotation system, management and management support and the us and them culture that was discussed in more detail in the previous section and carried through to the next discussion on recommendations.

The low responses to Item 11 and rather neutral response to Item 12 again relates to the fact that a functional and welladministered performance management, feedback system and staff development system seem to be absent within public hospitals. This low response links well with the view of participants during focus group interviews that there are very little promotion and development opportunities within the hospital. This perception has a negative impact on employee productivity and ultimately customer satisfaction and is thus very problematic.

\section{RECOMMENDATIONS}

In line with the above findings, the following general recommendations are made in order to enhance management effectiveness and employee wellness in public hospitals.

\section{Feedback}

It is recommended that feedback regarding all findings and processes within a hospital should be given to all employees as soon as possible. This will create a climate of mutual understanding and trust. From the study it became apparent that the "lack of knowing what is going on" is one of the biggest reasons for emotional disease amongst employees.

\section{Management/Union relationship}

The importance of mutual commitment and cooperation of all parties cannot be overstated if a hospital wants to be successful. It is suggested that a code of conduct between management and unions should be established as a matter of urgency before any attempt is made to bring about change. This process should preferably be started during a relationship building and conflict resolution workshop. The use of an outside facilitator to conduct this workshop must be strongly recommended.

\section{Strategic planning}

No organisation can effectively function without clearly defined borders and a well-set sense of direction. Although it will be necessary to deviate from time to time in order to overcome obstacles, it is imperative that a future destination must be identified. The direction and precise location of this destination must then be clearly communicated in order to make it possible to reach the destination. A formal strategic planning session for public hospitals is therefore recommended. During such a workshop the overall aims of the hospital must be established and specific action plans to reach the goals must be agreed upon.

\section{Team building}

Teambuilding refers to all those activities aimed at improving the problem solving ability of group members by resolving task and interpersonal issues that impede the team's functioning. A teambuilding program is usually not initiated unless someone (the leader, a higher level manager, a team member or consultant) recognises that the group is having problems working productively as a team. It is therefore recommended that team-building sessions should take place with regularity. During such sessions specific attention should be given to addressing the interpersonal conflict between members of the team as well as defining and clarifying the strategic road ahead.

\section{Diversity Management - THE creation of a new Ethos}

Based on the rapid change in the health care industry and in public health as well as the findings on the "us and them" culture within the hospital, the authors very strongly recommended that a program during which a new hospital ethos can be created should be rolled out at public hospitals. During the program the various aspects of diversity and the "us and them" culture should also be addressed.

\section{Performance Management}

A performance management system for public hospitals should be developed that extends throughout the year. The system should however make provision for at least two checking systems that will identify performance gaps and suggest corrective action. These two checking systems are Performance Assessment and Development Assessment. A balanced scorecard approach can be used for this purpose.

\section{Management training}

Professional nurses with excellent technical ability and years of experience seem to have been promoted into managerial positions without the necessary management and supervisory training, development and coaching. Area- as well as unit managers indicated that they are aware and often frustrated by their inability and lack of general management knowledge and skill. It is strongly recommended that this group should be exposed to a management development program.

\section{Communication}

It is recommended that the internal communication system in public hospitals per se should be analysed and that a very specific communication strategy should be developed to ensure that the transformation process is not sabotaged.

\section{The Rotation system}

It is recommended that a well representative task team should be formed to develop a rotation system that is acceptable to all parties involved. The new system should take into account organisational as well as individual requirements and should specifically create an environment that is conducive to teamwork.

\section{Counselling service}

Due to the extreme amount of emotional distress and trauma that employees in public hospitals experience every day, it is suggested that a professional be appointed from outside the various hospitals to give employees the opportunity to debrief their feelings and emotions.

Evaluation of the impact of HIV/AIDS on medical personnel It is strongly recommended that the impact of HIV/AIDS (and the resulting high mortality rate in the hospital), has on medical personnel should be investigated. Based on the results of this investigation, action plans should be developed to help existing personnel cope with this reality. Recommendations should however also be made to tertiary institutions to prepare current students for the reality that they will be faced with once entering the medical discipline on a full time basis. 


\section{CONCLUSION}

This article reported on a study which valiantly attempted the difficult task of determining whether organisational effectiveness of public hospitals is the result of management processes, people wellness or a combination of both. Given the complexity of the study and variety of problem areas found, progress towards the overall aim was achieved. For instance, vital characteristics associated with organisational effectiveness of public hospitals were found to include visible leadership and a commitment towards training and development, teamwork, stakeholder involvement and innovation. Moreover, the use of self-assessment models was also felt to have positively impacted on organisational effectiveness.

If the findings outlined in this article are taken seriously and the subsequent recommendations made considered enthusiastically, the benefits for individual hospitals, the healthcare industry at large and eventually the care for patients in South Africa, can be phenomenal. However, due to time constraints, the value of the findings are limited, thereby suggesting that further work in this area would be of benefit.

\section{REFERENCES}

Babbie, E. (1992). The Practice of Social research. $6^{\text {th }}$ edition, Wadsworth Publishing Company: Belmont.

Bashein, B., Markus, M, and Ripley P. (1994). "Precondition for BPR success and how to prevent failures", Information Systems Management, Springs, pp. 7-13.

Bateson, J.E.G. (1992). Managing Services Marketing: Text and Readings, 2nd edition, Dryden: Orlando.

Buckingham, M. Coffman, C. (1999). First break all the rules: What the worlds greatest managers do differently. Simon and Schuster: New York.
Editor (1999). Health sector strategic framework 1999 - 2004 http://www.doh.gov.za/docs/policy-f.html

Laudon, K.C.; Laudon, J.P. (1998), Management information systems: New Approaches to Organization and Technology, $4^{\text {th }}$ edition, Prentice Hall, International: New Jersey.

Lincoln, Y.S. \& Guba, E.G. Naturalistic Inquiry. Beverly Hills, CA: Sage. In Denzin, N.K. \& Lincoln, Y.S. (eds). (1985) Handbook of qualitative research. Thousand Oaks: Sage.

Marguardt, M.J. (1999). The Global advantage. How world-class organisations improve performance through globalisation. Gulf Publishing Company: Houston Texas.

Miles, R.H. (1980). Macro Organisational Behaviour. Scott Foresman: London.

Peters, T.J., Waterman, R.H., (1982). In Search of Excellence: Lessons from America's Best-run Companies. Harper \& Row: New York.

Pricewaterhousecoopers, (1999), "Healthcast 2010- Smaller world, bigger expectations" http://www.pwc/ health.com

Robbins, S.P. (1987). Organization Theory: Structure, Design, and Applications. Prentice-Hall: Englewood Cliffs, NJ.

Rubin, H.J.; Rubin, I.S. (1995). Qualitative Interviewing. The art of hearing data. Thousand Oaks: Sage.

Rumford, D. (1996), SoulShaping. Tyndale House Publishers, Inc: Wheaton, Illinois.

South African Yearbook. (1999). http://www.gov.za/yearbook/ health.htm.

Stewart, R., (1996). Leading in the NHS. A Practical Guide. $2^{\text {nd }}$ ed., Macmillan Business: Basingstoke.

Steward, T. (2001), The Wealth of Knowledge. Nicholas Brealy Publishing: London.

Talwar, R. (1993). "Business Re-engineering - a Strategy driven Approach", Long Range Planning, Vol. 26, No.6 pp.22-40.

Thomson, K. (1998), Emotional Capital. Capstone Publishing Limited: Oxford United Kingdom.

Ulrich, D. (1999). Results Based Leadership. Harvard Business School Press: Boston, Massachusetts 